\title{
Preventive Medicine
}

National Cancer Institute

\section{Source}

National Cancer Institute. Preventive Medicine. NCI Thesaurus. Code C17011.

A branch of medicine that focuses on disease prevention. 